\title{
Redefining trauma in an African context: A challenge to pastoral care
}

\begin{abstract}
Authors:
Ray G. Motsi ${ }^{1}$

Maake J. Masango ${ }^{1}$

Affiliations:

${ }^{1}$ Department of Practical

Theology, University of

Pretoria, South Africa

Note:

This article has been adapted from Ray Motsi's PhD dissertation, which was completed under the supervision of Prof. Maake Masango, University of Pretoria, South Africa.

\section{Correspondence to: Maake Masango \\ Email: \\ maake.masango@up.ac.za}

Postal address:

PO Box 84173, Greenside

2034, South Africa

Date:

Received: 09 Sept. 2010

Accepted: 24 Sept. 2011

Published: 09 May 2012

How to cite this article: Motsi, R.G. \& Masango, M.J., 2012, 'Redefining trauma in an African context: A challenge to pastoral care', HTS Teologiese Studies/ Theological Studies 68(1), Art. \#955, 8 pages. http:// dx.doi.org/10.4102/hts. v68i1.955
\end{abstract}

C 2012. The Authors. Licensee: AOSIS OpenJournals. This work is licensed under the Creative Commons Attribution License.
The article attempted to analyse critically the definition of trauma as it is used in the Western medical and psychiatry contexts in order to come up with an appropriate African definition. This was undertaken with the view to demonstrate that the Western worldview is different from the African worldview. Superimposing solutions or providing pre-packed answers to unique African problems will lead only to re-traumatisation, whereas cultural sensitivity and the right diagnosis will lead to the correct treatment. The driving force behind this article was therefore to aim to be relevant, effective and contextual in all African-based pastoral care.

\section{Introduction}

Trauma issues and trauma treatment have become topical in Africa as a result of the political, social and economic instabilities that are common in the region. From a pastoral care perspective there is need to review and raise the philosophical argument about the relevance of humanitarian intervention, specifically in regard to the approach and treatment used. The Western medical and psychiatry fields view a person on the basis of an egocentric approach, but their African counterparts do so from a socio-centric perspective. A worldview is defined as how different people view their reality and therefore it is critical to accept that the Western worldview is different from the African one. The definition of trauma and the associated post-traumatic stress disorder (PTSD) diagnosis are at the centre of this debate. Do these represent the African perspective and if not what should be used in their place?

Africans view a person from a socio-centric perspective because a person is part of the bigger whole. An individual is an individual because he or she belongs to others in the community. The African view thus understands trauma to be a problem that affects the whole person and the whole community. Western philosophy, on the other hand, says a person is simply composed of soul and body and that trauma is a thing of the mind. Therefore, redefining trauma in light of this African viewpoint is critical and will enhance our caring of the many traumatised millions who desperately need help on this continent.

\section{The historical definition of trauma}

In the last 50 years, the concept of trauma and stress has become part of a discourse that is used commonly in the media coverage of wars, conflicts and natural disasters (ed. Becker 2000:12). In academic halls of higher learning, discussions of trauma have been left to the psychological and medical fields and have become a responsibility of those with professional skills and training. It has therefore become the domain of the mental health professionals who have reduced it to individual problems that are psychological nature (ed. Becker 2000:13). Western psychiatric and psychological medical studies have spearheaded the work on trauma and influenced most of the international world. Their contribution is priceless and needs to be commended. In his book, Introduction to pastoral care, Gerkin (1997) mentions that the Church only came into the picture later in the process, after the field of psychiatry was in full flight. Indeed, the field of practical theology is a fairly new one, let alone pastoral care. Therefore, a discussion about the clergy and other social workers being involved in trauma debate may be a novel idea but it is still necessary. We believe it is time for the Church to be involved and have a say because of the Church's proximity to the public and its role in the community. Because the church is involved in Pastoral care to trauma victims due to the reasons mentioned above it should therefore understand what this problem is and how to comprehensively deal with it.

The concept of trauma has been clearly described in the book Traumatology of Grieving: Conceptual theoretical and Treatment Foundations edited by Carl Figley (1999), an American psychologist who wrote extensively on the subject. He said, 'the most important factor in the experience of trauma is what occurs within the individual's mind; that is, post-traumatic cognitive processing' (ed. Becker 2000:44). Figley highlighted the way in which the western world view perceives a person 
as an individual hence; the psychological and psychiatric approaches perceive a person as an egocentric self, comprising the mind and body (ibid). This Western, dualistic worldview separates uncommon events occurring in the body or mind into two broader psychopathological categories: organic and psychological disorders. This dualism was made popular by Rene Descartes (1596-1650), a French physicist and philosopher who founded the school of philosophy known as Cartesian Dualism. Descartes made a distinction between spirit and matter and rejected philosophical authority and tradition as he relied exclusively on reason (Harvey 1946:219). This egocentric self refers to an understanding of the individual as a self-contained, autonomous entity. Psychological normality and abnormality are seen as internal processes that are also limited to the self. As such, the Western view disregards the social origins and path of mental illness.

Most of the world's population outside of the West holds onto a more socio-centric conception of the self, where individuals exist within networks of social relationships. It is from this relationship that they derive self-worth, self-fulfilment and self-control. In this context and model, reciprocal and interpersonal privileges or obligations are more important than the rights of individuals (Losi 2000). This is critical in the sense that the way in which we define trauma is influenced by how we perceive reality.

The Concise Oxford English Dictionary (ed. Soanes \& Stevenson 2003) defines trauma as 'an anxiety disorder caused by the major personal stress of a serious and/or frightening event such as an injury, assault, rape, exposure to warfare or a disaster involving casualties'. The broad use of the diagnosis is seen by some as pathologising, which is a normal response to traumatic situations. One thing to note from this definition is that it does not limit the symptoms of trauma to individual feelings alone, but to the nature of the event as well. Yet, it does not mention the community or communal nature of an African life. From the Western perspective, culture is interpreted as a set of beliefs, or secondary elements which are superimposed on the tangible reality of biology. Such thoughts are considered superstitious. We aim to highlight the role of the worldview in all of these perspectives, for it is clear to many of us that we all interpret reality through our own worldviews. Therefore, this proposal suggests strongly that respect must be given to different worldviews and cultures because there is no culture that is better than the other.

Traumatised people the world over need help so that they can understand their pain and suffering and develop specific strategies for dealing with it. Pre-packed universal interpretations, definitions and approaches to psychological suffering do not bring the necessary help. Losi (cited in ed. Becker 2000:14) concluded that, 'the belief in science and in the power of the international scientific community is so strong that it tends to marginalize local knowledge'. Therefore, a community-based and culturally sensitive approach is needed in dealing with traumatised people.
Common trauma symptoms include the persistent reexperiencing of the traumatic event, persistent avoidance of stimuli associated with the event, numbing of general responsiveness, and signs of increased arousal. In spite of the fact that all these symptoms may be observed in all traumatised people, including Africans, relying on the symptoms alone should not be the only way to assess or diagnose trauma.

\section{The traditional African worldview}

In the African worldview, life is perceived as holistic rather than being compartmentalised. A human being is perceived as a whole person whose core is his or her spirituality - there is no distinction between religious or secular life. Contrary to the individualistic approach of the Western worldview, African people tend to view life in a communal way. Harvey Sindima (cited in Magesa 1997) suggested that:

we cannot understand a person as an individual, and we cannot have personal identity without reference to other persons ... the notion of being together is intended to emphasize that life is the actuality of living in the present together with people, other creatures and the earth whether dead or alive. (p. 53)

Mulago (cited in Magesa 1997) confirms Magesa's assertion by adding to this debate:

The life of the individual can only be grasped as it is shared. A member of the tribe, clan, and the family knows that he [sic] does not live to himself, but within the community. (p. 64)

This is exactly the worldview of the majority of African people.

As such, we can define community as 'relationships of individuals founded on common factor, or factors. These factors can be classified according to social experiences as defined by the group and the grid' (Shorter 1998:12). Whilst Mugambi and Kirima (1976) define community as that which is:

made up of individuals who are directly related to one another, either through blood or through marriage. Kinship system is like $[a]$ closely woven network which stretches in every direction including all who live in the community. (p. 13)

Here, Mugambi and Kirima provide an African worldview of what a community is and it is encouraging to observe that the gist of what they are saying is the same as Shorter's Western definition above. John Mbiti (1969:102) confirms this similarity when he states that an 'African community is based on kinship through blood and betrothal. It is the kinship which controls social relationships between people in a given group which makes a community'.

The community fosters fairness, equality and basic rights for its members and encourages and promotes cultural diversity. Mbiti (1969), who is an authority on African traditional values and worldview, explains the community as that in which the traditional life of an individual cannot exist alone; it can only exist corporately. One owes one's existence to others, including contemporaries and those of past generations. One is part of the whole. The community makes, creates, 
or even produces the individual, who, in turn, depends on the corporate group (Mbiti 1969). Only in terms of others does the individual become conscious of one's own being, duties, privileges and responsibility towards one's self. The concept of 'mundu' in Kiswahili or 'ubuntu' in Ndebele is central to what Mbiti is explaining, in that whatever happens to the individual happens to the whole group. The individual can only say, 'I am because we are and since we are, therefore I am' (Mbiti 1969:11). Thus, the African view of an individual is one which is intertwined with the whole tribe and community and cannot be understood in isolation. Often, the Western view misses this perspective because it does not realise that issues of guilt and shame exist in a sense of collective responsibility. Indeed, Shorter (1998:43) alludes that within the Afrcian worldview, the individual appears as the passive object of an external agency which becomes the diffused image of selfhood.

Therefore pain and stress in Africa is perceived by the people as a problem affecting the community and not just individuals. This is true especially if society fails to provide answers and support to the people who are helpless and desperate. Psychology will not be able to bring about the necessary community comfort and restoration that is required to meet the traditional African expectations.

Most of our people in Africa exist within networks of social relationships from which they derive their self worth, selfcontrol, sense of belonging and sense of security. In this sociocentric model, reciprocal and interpersonal privileges and obligations are more important than the rights of individuals (Losi 2000). An emphasis on the individual is a foreign concept to the peoples of Africa, especially the people of Zimbabwe. Mbiti (1969) would disagree with Descartes on the aspect of dualism because, as Africans, our sense of being is derived from our sense of belonging and community in a physical and spiritual sense. A sense of community and belonging is fundamental amongst the African cultures. Dualism, which is foundational in psychology and psychiatry, will lead to the mistreatment of African trauma survivors as they become alienated from the community. As we steer away from the field of psychiatry and medical diagnosis, the African holistic worldview and approach should emerge as the most relevant philosophy and a methodology of choice. Globally, most groups of people experience any suffering including trauma as integration of body and spirit and in asocial context.

The formulation of proper practical theology methodology is therefore critical. Theology can borrow from psychiatric results, which can enhance pastoral care and counselling if Africans engaging in it do not become reactionaries and 'throw out the baby with the bath water'.

\section{Describing trauma from it symptoms}

Symptoms of a traumatic condition include trouble sleeping, difficulty concentrating, being easily startled, intensified alertness, increased anxiety, sweating and a rapid heartbeat, amongst many others. Other bodily reactions are digestive complaints, stomach aches and headaches, which may include migraines. Emotions are numbed and one's memory seems to play tricks as one often experiences anxiety as a horrible dream which will soon pass away (Hybels-Steer 1995:34).

Intrusions (i.e. a flood of memories and images) and denial are said to be emotional responses which are unique to traumatic experiences. Denial comes into play when one is unable to cope with the strength of certain emotions in times of great distress, especially trauma. Hybels-Steer (1995) suggests that in the early stages of trauma after the event, denial is seen as a 'friend' as it becomes a coping mechanism. Traumatic memory is perceived as a still frame and a mental picture. Hybels-Steer (1995) goes on to explain that this shot is a living colour which stands stark in one's memory and is filled with intensity of emotions.

\section{Focusing on traumatic events}

Carlson et al. (1997) identified four aspects which must be considered in this research as that which would result in a victim being traumatised. These are, (1) the perception of the event as having a highly negative valence, (2) the suddenness of the experience, (3) the inability of the individual or group to control the event and (4) the subsequent threat to the individual's physical safety and psychic integrity (see also Carlson 1997:28). We would like to add two aspects to this list: the unavoidability of the event and the threat to life or destruction of property or possessions. The destruction of one's possessions is as traumatising as being physically hurt because it affects the person in the same way, if not worse. The psychological pain of a traumatic event involves damage or threat to an individual's psychic integrity or sense of self (Carlson 1997:29). An example of this could be a woman who is raped and becomes traumatised as a result. Such an experience might damage her sense of self because of the shame of being raped and the guilt over any responsibility she feels for what happened. There is anguish over the inability to protect one's self from an unwanted and negative experience. In most of the cases, these events are so sudden that it does not give one an opportunity to adjust or reflect on it before it happens. The inability to control an experience is a defining element of trauma. Research on both animals and humans has shown that both are distressed by a lack of controllability of events and certain experiences (Carlson 1997:233). Yet, the same experiences and events do not cause the same effects to all people.

All six aspects mentioned above form part of the qualitative phenomenology that makes up the traumatic experience. These six aspects stand out as the prominent evidence of traumatic events, and therefore trauma should not be defined according to medical psychiatry terms or be limited to PTSD alone.

\section{Torture as a political tool in Africa}

Torture and political violence in Africa are amongst the greatest causes of trauma on the continent and we must therefore make a concerted effort to eradicate it. This kind 
of trauma is difficult to deal with because it is not simply a medical or psychological problem but, rather, a socio-political issue. Culture and religion are also contributors to this ethos of violence. As one investigates any trauma that is the result of torture, one may be surprised by how the torturous attack was deliberate and was aimed at destroying the individual and community.

The United Nations declaration and the Tokyo Declaration of the World Medical Association are normally used as standard in defining torture and this is the gist of what they say:

torture is a dynamic process beginning with arrest, involving a sequence of traumatic events that may take place at different times and places, and ending with the release or demise of the victim. (ed. Basoglu 1992:57)

In Latin, torture is torguere, which means 'to cause to turn or twist' and is used in the context of one who is attempting to extract testimony and/or evidence or to repress opposing religion or political view. In Cambodia, torture is tieru na kam and is said to have been derived from the Buddhist term for karma, which is defined as the individual's actions or thoughts, often of an evil nature, in a prior existence that affects life in the present. Khmer Rouge soldiers in Cambodia subjected civilians to starvation and brainwashing as a process of subduing them and extracting information from the population. This was done to make the civilians unable to stand on their own, ensuring that they would be dependent on the soldiers (Goldfeld et al., cited in ed. Basoglu 1992:256).

In our research, we were surprised by the heinous nature of the words used in these languages to represent torture or tortuous acts and especially by the way in which it reveals the evil intentions of the perpetrator. To the horror of all, it seems clear from the Cambodian language that these thoughts are evil and have prior existence which indicates some form of preplanning. As we continued in this taxing journey, we discovered that the approach mentioned in the definition above is similar to that found in most massacres and genocide in Africa. In this sense, we intend to pioneer an African approach to torture and resultant trauma, which centres on a psychosocial approach as an attempt to be relevant. This is a proven scientific approach as argued by many scholars, including Saporta and Van der Kolk (cited in ed. Basoglu 1992:151). As such, we believe this approach will enhance an African spirituality and renewal. When cultural and social support, which is the first line of defence against trauma, is disenabled, a sudden overwhelming collapse of the traditional system ensues.

\section{Building a case for a relevant African approach}

There is a problem of medicalising the sequence of basic human rights responses to political oppression and human cruelty. It shifts attention away from human rights and the prevention of violence to the objectifying of a politically neutral diagnosis of modern medicine. Basoglu (ed. 1992:24) confirmed the recent trends that suggest that biomedical science has pushed scientific investigations further away from addressing meaningful and important social problems.
The new approaches include issues related to prevention and empirical understanding of violence and torturers and the organisations and societies from which they come.

There is an ongoing argument amongst psychologists about whether the application of the PTSD approach is relevant and accurate. In their book entitled Traumatic stress: The effects overwhelming experiences on mind, body and society, Van der Kolk, McFarlane and Weisaeth (eds. 2007:399) argued that psychological trauma and reactions to it have been legitimised in the Western medical diagnostic system and quoted the American Psychiatric Association publications of 1980 and 1994 as their examples. De Vries (cited in Van der Kolk et al. 2007:399) continues to suggest that PTSD must serve as a model for correcting the de-contextualised aspects of today's taxonomic systems. It is stated:

de-contextualization draws our attention away from an overly concrete definition of psychological illness as a thing in itself, bringing us back to the person's experience and the meaning which he or she assigns to it. (Nemiah 1989:1528)

Nemiah affirms the position taken by others scholars indicated above. They suggest therefore that PTSD diagnostic proponents should allow us to focus on the life history of the individual in the context of the society and culture in which they live. PTSD should not be described as process of illness based on the intrinsic nature of the person alone, but rather as one that is based on the person's socio-cultural interaction over time (eds. Van der Kolk et al. 2007:399).

Adverse events resulting from political repression and violence span a relatively long period of time in Africa's history and this has led to the repeated traumatisation of individuals. By definition, torture, in particular, is a complex phenomenon with interacting social, culture, political, medical, psychological and biological dimensions. Yet, the term PTSD is not readily applied to those who have experienced political violence or torture because torture is only part of a series of ongoing traumatic situations for those survivors. The shortcomings of this diagnosis of trauma is the term 'post', which, in Basoglu's (ed. 1992:7) expert opinion, fails as an accurate description, for it ignores the survivor's continuous struggles with trauma, sometimes even 50 years after the event took place, as is the case with many Holocaust survivors. Whilst it may be true that 'post' is describing the event in and of itself and not the experience - for these events may have stopped in the eyes of the general public - but, to the victims, they have not ended due to emotional scars, disabilities, disappearances and destruction. The world of the survivors has been changed completely and negatively by the violations they underwent and they are forced to come to terms with a new reality - a new 'normal'. Having to look at bullet wounds, or living the rest of one's life with one eye, a broken leg, or having no teeth is not 'post', but ongoing pain or suffering. These are some of the glaring realities in Africa which need no digging up, as they are always there for all to see.

The ongoing discussion about how useful or limiting this diagnosis of PTSD is and how widely it should be used, 
especially in ongoing large-scale national traumatic events in both the Western and non-Western societies should be a relevant debate. It should help and spur us on in realising an empirical framework that is uniquely and contextually relevant.

One of the arguments in this regard is that in the developing world it is a luxury to afford a one-to-one opportunity for counselling, when faced with millions of trauma survivors across the continent. Dr Anne Kubai, who is Kenyan, spent more than five years in Rwanda working amongst the survivors of the Rwanda genocide. It is claimed that more than eight hundred thousand people were massacred in the genocide and there is no way she feasibly could use PTSD as the bases for assessment of the trauma they experienced (Dr A. Kubai pers. comm. interview, 27 February 2009). There are literally millions of survivors who needed and still need help today. Other related conditions of the victim or survivor before, during and after the traumatic experience should also be considered. African countries do not have the kind of expertise that is needed to assess traumatic experience on the bases of PTSD. As such, the impact of the socio-political situation plays a major role in influencing the response to traumatic experiencing.

\section{The role of culture in mental health problems}

Research on stress, trauma and their interaction with psychology, sociology and physiology has demonstrated that the impact of stress and trauma encompasses biological, psychological, social and cultural phenomena (Herman 1997). Social trauma can best be addressed by the psychosocial approach, which is an analysis of the web of social relations and interactions of both the individual and the community in ongoing mental health problems. It is the positive evaluation of the self in the social context, as well as social support, that correct the negative effects of stressful events. Culture plays a key role in how individuals cope with potential traumatising experiences by providing the context in which social support and other positive and uplifting events can be experienced. The interactions of an individual and his or her environment and community play a significant role in determining whether that person is able to cope with the traumatising experience that set the stage for the development of PTSD. Culture can be a double-edged sword; because human beings depend on it, its loss becomes a traumatic experience. The power of culture as a protector, integrator and security system is evident in studies where the degree of culture assimilation is a key variable (Brown \& Prudo, cited in Van der Kolk et al. 2007:400-401).

Culture provides the community with a system of values, lifestyles and knowledge. The disruption of these aspects will have a disastrous effect on its members. Culture is powerful and resilient to the stress of the environment and is therefore often resistant to change. And herein lies the biggest challenge. Normally, cultural change comes through necessity, youthfulness and interaction. However, in many of our African cultures, family and community resources become primary sources of rehabilitation and necessary healing. This is even more so when one recognises that skilled medical personnel are unavailable across much of the continent. But even when they are, this rehabilitation demands comprehensive understanding and skill of interpersonal, family and community variables (ed. Basoglu 1992:491). The argument here is that there is a danger that responses to trauma may be underestimated by limiting them only to psychological trauma, which eventually results a diagnosis of PTSD. Trauma impacts body, mind and spirit and when it is experienced at the level of a community, the whole immediate society is affected. This is especially the case in an African context where life is based on interdependence rather than individual self-reliance.

Herman (1992:1) commented on atrocities (such as mass murder) as violations with a social impact which are too terrible to utter aloud - giving meaning to the phrase 'unspeakable acts'. Quite often people would rather keep quiet than talk about it. Thus, there is need to understand violence and torture and related rape experiences from a socio-cultural and political background, as well as from a medical perspectives. Mollica and Son (cited in ed. Basoglu 1992:256) give examples of Vietnamese women who were raped by Khmer Rouge soldiers. A Vietnamese proverb regarding rape summarises the severity of the damage in this way, 'someone ate out of my bowl and left it dirty'. Most Cambodian women and children who suffered through rape also suffered through the loss of their dignity (ed. Basoglu 1992). And, as a result, the victims did not say anything. This is due to the fact that, in their culture, women who are raped are dishonoured and have lost their self-respect and selfworth, forcing them to bear the pain of shame and the guilt alone. Sometimes the rape was not a single incident by one man, but occurred as group rape in an abuse of power by the soldiers. Similarly, a South American woman who was sexually tortured as a political prisoner tells her story:

I was interrogated five times by men and every single time I was completely naked. During each of the five interrogations I started menstruating even though it was not the right time for me. Maybe I was too nervous and it resulted with [sic] me always being covered with blood. There were always five torturers who forced me to always look them in the eyes. They then mauled me all over my body and asked me to walk in front of them as they line [sic] up watching me and still making [sic] me look them in the eyes. It felt so incredibly humiliating. (Mollica \& Son, cited in ed. Basoglu 1992:257)

The physical injuries sustained by trauma victims are often present for life and have the effect of continuing the torture long after the detention, beatings, incident and/or event. The aim of torture is to destroy the survivor's mind and will and it is therefore not always easy for survivors to move on with their lives (ed. Basoglu 1992:5).

Through this article, we seek to highlight the traditional cultural impact of gender and sexual violence on survivors as a result of cultural beliefs and attitudes in primary cultures of the world. The insensitivity, chauvinism and patronisation 
of men towards women in Africa needs to be confronted in order to address some of these cultural injustices. Cultures are dynamic, not static, and therefore some of these attitudes need to change. It is not only historians of culture who note that people are yearning to integrate all their past into a meaningful unity (Volf 2006). A good deal of trauma literature echoes the same idea. Van der Kolk et al. (2007) suggest that because survivors of trauma cannot, like anybody else, change their past, they must place traumatic memories in the proper context and reconstruct them in a personal and meaningful way - 'Giving meaning is a central goal of therapy' (Volf 2006:184). Similarly, Janoff-Bulman and Frieze (cited in Kleber \& Brown 1992:144) suggest that when dealing with traumatic experiences, the world of certainties disappears and 'the assumptive world' must be reconstructed.

In a study conducted with 77 women who were survivors of incest, it was discovered that they continued to look for understanding and meaning even though the incidents happened 20 years before (Kleber \& Brown 1992:145). Their quest for meaning created painful emotions and displeasure. It was suggested by Freud (cited in Kleber \& Brown 1992:76) that re-experiencing trauma is directly related to the search for meaning. Holocaust testimonies entitled 'The ruins of memory', which are based on videotaped testimonies of the holocaust survivors conducted by Lawrence Langer (cited in Volf 2006), evince this truth. Written accounts of the life in the Nazi concentration camps often seek to integrate the holocaust experiences into a larger structure of meaning. Langer (cited in Volf 2006:180) goes on to suggest that these testimonies stand as 'the indomitable human spirit'. This seems to be a sign of growing through suffering, which, in itself, is proof that moral integrity is possible even under extreme duress. Yet, these experiences refuse to integrate into a larger narrative of meaningful life. In cultural terms, the community provides the basis for a sense of belonging and fosters a common identity. Culture provides a health maintenance system, the function of which is to assure the adequate sharing of values, resources and social relationships. There are structures and a progression through the lifecycle (Whiting \& Whiting, cited in Van der Kolk et al. 2007:400).

\section{Establishing control}

We would like to define control as an active command of the circumstances around which one's life is ordered. Rothbaum et al. (cited in Carlson 1997:70) define control as 'the influence of both external realities and the personal consequences of these realities'. These two definitions provide pivotal contributions which distinguish between primary control that is, the shaping of physical, social or behavioural reality and secondary control, which is the adaptation to the existing reality. It is envisaged that the process of attributing meaning creates a feeling of control and, in so doing, promotes wellbeing. The more control people can exercise in a situation, the less they suffer from diverging symptoms and cope better in general. This has been concluded by many scholars whose studies focused on the phenomenon of control and traumatic experiences, including those conducted by Rothbaum et al. (cited in Carlson 2007) and Weisz, Rothbaum and Blackburn (cited in Kleber \& Brown 1992:147). There is a necessity to pursue the quest for control a little more in order to identify the effects of trauma on both the individual and the community.

To this end, there are three closely related propositions concerning control which are given by Kleber and Brown (1992) in their book entitled, coping with trauma. These are:

- After a traumatic situation, the person searches for the meaning of what has happened.

- The person attempts to regain control of the situation.

- Social-psychological process plays an important role in the effects and the process of coping with a shock.

Kleber and Brown (1992:143) argue that that these propositions have been clarified by theoretical and empirical findings of several studies in the field of social psychology and stress research. Thus, if it is true that a person behaves in accordance with his beliefs and assumptions, it follows that social context plays a pivotal role in providing meaning and control. Without meaning there will not be control and coping which leads to healing.

Similarly, Carlson (1997:69) arrived at the theory of 'learned helplessness' after extensive research on the behaviour of dogs and rats, which led to the identification of the condition of helplessness in human behaviour that we know as depression. Learned helplessness results in a condition of powerlessness in the victims. On the other hand, the coping process can be considered an attempt to regain control over one's own existence. People strive to reconcile old schemata with new information through a search for meaning. Finding a means of curbing the chaos and of ordering the world is to interpret the circumstances in such a way that a grip on the situation is regained (Kleber \& Brown 1992:155). This is very helpful because it sheds some light on the plight of the survivors and their struggle to understand what happened to them in their quest for control and meaning. Combat, torture, rape and massacres lead to humiliation, loss of self and damage to one's sense of belonging, especially because at the point of trauma experience, the opinion of the victim counts for nothing, as the reason behind inflicting trauma is often to demonstrate contempt, induce humiliation and violate one's autonomy and dignity.

\section{Cultural perspectives on trauma}

The developing world, and Africa in particular, is unique in that inter-dependency of community and family ties are often stronger than in the developed world. People from traditional cultures are more likely to perceive themselves as part of a larger whole and trauma and illness are viewed as being externally caused and ongoing, which is linked to the larger society.

Family is the first line of defence against trauma and, with this, culture is the identity provider in the community. If 
family and culture fail to provide the safety net, other 'ugly' models of identity formation and social group formation take their place. The roles and status that had previously organised the system may have no further meaning. When cultural protection and security fail, the individual's problems are proportional to the cultural disintegration. The avenues of vulnerability resulting from trauma follow the routes vacated by culture. Normally, the situation is compounded by the problem that, in most areas of the world, the population is often physically depleted and fatigued in times of cultural disintegration as well. For example, Van der Kolk et al. (2007) wrote extensively about the people of Bosnia, Somalia and Rwanda, relating how they were physically and psychologically traumatised as a result of the protracted wars they had been fighting.

Different violent and political incidents can have distinctive cultural meanings and thus also have specific impacts on the people involved. It is said that most of the witnesses at the South African Truth and Reconciliation Commission presented a mixture of issues related to social, psychological and medical problems (Bloomfield, Barnes \& Huyse 2003; Villa-Vicencio \& Doxtader 2004:92). Most of the people who experienced past traumas, such as torture or abuse, have been overshadowed by current psychological personal social battles. This makes it difficult and, quite often, actually complicates the original traumatic problem. Secondary and associative symptoms of trauma begin to manifest. The ability to draw direct causal links between the initial traumatic incident and the present difficulties experienced by some survivors generally has been complicated by the protracted period of time that has passed since the violations occurred. The way the community and individuals interpret traumatic events is vitally important when considering strategies for healing.

Of great interest to this research is the comment made by psychologist Michael Wessels (cited in Bloomfield, Barnes \& Huyse 2003:69), as he reflected on his experiences of working in sub-Saharan Africa. He observed that spirituality and community are at the centre of life in the region. An Angolan boy, whose parents were killed in political violence, may not need to talk about his personal experience of loss but, rather, the major stressor of the spiritual discord and lack of means to provide decent burial for his parents (Mbiti 1969). Interestingly, our primary context - that of Zimbabwe - is also mentioned by Wessels. Commenting on the massacres that occurred in Matabeleland, he said that:

Zimbabwean survivors of the Matabeleland massacre consider the corruption of community values and lack of cohesiveness as more offensive and disturbing than any other aspect of the conflict. It is the loss that is still being mourned years after the massacres of the 1982 to 1987. (Wessels, cited in Bloomfield, Barnes \& Huyse 2003:78)

The reactions depend on a personal pre-traumatic personality structure, temperament and the extended community support structure. The pre-traumatic period and the personality structure of the individual have a role to play in the lives of those who find themselves face to face with these experiences.

\section{Conclusion}

\section{Redefining trauma}

Traumatic and/or stressful experiences are defined by some scholars as the events and incidents that are physically, emotionally and mentally difficult to process and are considered as harmful. For most individuals and communities, these experiences disrupt lives and have overwhelming levels of negative impact and dangers. Often, it is almost impossible for the survivors to adjust and adapt without external help. Repeated exposure to violence or any stressful circumstances or chains of such events and experiences may increasingly deplete human and cultural resources. Individuals and/or communities experience a downward spiral of response and consequences that are difficult to reverse following a trauma. This comes from the meaning of the word itself, which shows that it has an intention to harm and 'squeeze' its victim, with the result affecting the person in his or her totality. It also has strong social and spiritual connotations which cannot easily be pushed aside. Therefore trauma has to be redefined in the African socio-centric cultural perspective using the African worldview.

This redefinition must include the effects of natural disasters, social, economic, political, gender and age abuses, as well as violations and injustices on issues that affect all our lives. The events and their impact on the individuals and community must be taken into consideration. A threat to family and community overrides a threat to self. As such, we thought initially that trauma in the African perspective should be defined as a 'mental and health problem', or simply a mental health crisis, which may have been caused by a natural disaster, political violence, abuse, loss and/ or spiritual issues. However, the term 'mental health' has negative connotations in Africa, which originate from stigmatisation. The problem affects the person physically socially, mentally and spiritually (i.e. the whole person) and as a result the community is also affected problematically. We therefore propose that this kind of trauma in Africa be called psychosocial crises. Even though many people may be affected, there is no one treatment that fits all. The majority may need psychosocial support in varying degrees, with a few needing specialised medical attention and still others that would not need any help as long as family and community support was offered. Possessing cultural sensitivity and understanding the needs of the people will help the pastoral care provider to use an integrated approach.

Psychosocial programmes that are both non-medical in their focus and community-based are likely to increase the survivors' own coping resources by addressing the needs of the whole community.

\section{Acknowledgements Competing interests}

The authors declare that they have no financial or personal relationship(s) which may have inappropriately influenced them in writing this article. 


\section{Authors' contributions}

This article has been adapted from the PhD dissertation of R.M. (University of Pretoria) which was completed under the supervision of M.J.M. (University of Pretoria).

\section{References}

Basoglu, M. (ed.), 1992, Torture and its consequences: Current treatment approaches, Cambridge University Press, Cambridge.

Becker, C. (ed.), 2000, Psychosocial notebook: Psychosocial and trauma response in war-torn societies: The case of Kosovo, International Organization for Migration, Geneva.

Bloomfield, D., Barnes, T. \& Huyse, L. (eds.), 2003, Reconciliation after violent conflict: A handbook, IDEA International, Stockholm.

Carlson, E.B., 1997, Trauma assessment: A clinician's guide, The Guilford Press, New York, NY. http://dx.doi.org/10.1177/1077559597002003009

Carlson, E.B., Furby, L., Armstrong, J.A. \& Shlaes, J., 1997, 'A conceptual framework for the long term psychological effects of trauma childhood abuse', Child Maltreatment 2(3), 272-295.

Figley C., (ed.), 1999, Traumatology of Grieving: Conceptual theoretical and Treatment Foundations, Brunner Mazel, Florida.

Gerkin, C., 1997, Introduction to pastoral care, Abingdon Press, Nashville, TN.
Harvey, P., 1946, The Oxford companion to English literature, 3rd edn., Oxford University Press, Oxford.

Herman, J., 1997, Trauma and recovery: The aftermath of violence from domestic abuse to political terror, Basic Books, London.

Hybels-Steer, M., 1959, Aftermath: Survive and overcome trauma, Simon \& Schuster New York, NY.

Kleber, R.J. \& Brown, D., 1992, Coping with trauma, Zwets and Zetlinger, Amsterdam. Losi, N., 2000, Vite Altrove: Migrazione e Disagio Psichico, Feltrinelli, Milan.

Magesa L., 1997, African Religion: The moral Traditions of Abundant Life, Orbis Book Maryknoll.

Mbiti, J., 1969, African religions and philosophy, Heinmann, Ibadan.

Mugambi, J. \& Kirima, N., 1976, The African religious heritage, Oxford University Press, Oxford.

Nemiah, J., 1989, 'Janet redivivus: The centenary of L'automatisme psychologique', American Journal of Psychiatry 146(12), 1527-1529.

Shorter, A., 1998, African culture an overview: Social-cultural anthropology, Paulines, Nairobi.

Soanes, C. \& Stevenson, A. (ed.), 2004, The Concise Oxford English Dictionary, Oxford University Press, Oxford.

Van der Kolk, B.A, Mcfarlane, A.C. \& Weisaeth, L. (eds.), 2007, Trauma Stress: The effects overwhelming experiences on mind, body and society, The Guildford Process, New York, NY

Villa-Vicencio, C. \& Doxtader, E., 2004, Pieces of the puzzle: Keywords reconciliation and transitional justice, Compress, Cape Town.

Volf, M., 2006, End of memory: Remembering rightly in a violent world, Eerdmans, Grand Rapids. 